ОЦЕНКА ВЗАИМОСВЯЗИ

СОДЕРЖАНИЯ ХИМИЧЕСКИХ ЭЛЕМЕНТОВ В ВОЛОСАХ И ХИМИЧЕСКОГО СОСТАВА РАЦИОНА У СТУДЕНТОВ ПЕРВОГО КУРСА РУДН

\author{
А.В. Гальченко ${ }^{1,2 *}$ М.Ю. Яковлев ${ }^{1}$, А.А. Скальный \\ А.А. Киричук ${ }^{1}$, О.Ю. Орлова ${ }^{3}$, Р. Алмасри ${ }^{1}$, \\ А.В. Баринов ${ }^{1}$, Н.В. Tuтов $^{1}$, T.В. Коробейникова ${ }^{4}$ \\ ${ }^{1}$ ФАОУ ВО «Российский университет дружбы народов», Москва \\ ${ }^{2}$ ФББУН «ФИЦ питания, биотехнологии и безопасности пищи», Москва \\ ${ }^{3}$ ФГАОУ ВО «Университет ИТМО», Санкт-Петербург \\ ${ }^{4} \mathrm{AHO}$ «Центр биотической медицины», Москва
}

РЕЗЮМЕ. Цель работы - определить взаимосвязь содержания химических элементов в волосах с характером питания. Обследовано 107 человек (75 женщин и 32 мужчины), студентов первого курса Российского университета дружбы народов из 33 стран мира. Средний возраст испытуемых составил 22 года. У обследованных произведен забор волос с затылочной части головы. Волосы проанализированы на качественный и количественный элементный состав методом масс-спектрометрии с индуцировано связанной плазмой. Проведена оценка усредненного рациона студентов методом частотного анализа с использованием программного обеспечения «Nutrilogic». Результаты исследования показали, что более половины студентов имели дефицит потребления P (61,68\%), I (57,01\%), Мо (75,70\%), Cr (78,50\%), холина (71,96\%). Наиболее сильные корреляции содержания химического элемента в волосах у мужчин с поступлением пищевых веществ обнаружены для (химический элемент в волосах - нутриент, зависимость, прямая или обратная, значение $p$ ) $\mathrm{W}-\mathrm{Mo}, \downarrow, 0,007$; Со - витамин В12, $\uparrow, 0,003$; Hg - $\beta$-каротин, $\downarrow$, 0,002; Mg - фолат, $\uparrow, 0,001 ; \mathrm{Mg}$ - пантотеновая кислота, $\downarrow$, 0,0001; Р - витамин В12, $\uparrow, 0,0001$; P - пантотеновая кислота, $\uparrow, 0,001$. Среди женщин подобных отношений обнаружено не было, за исключением концентраций бериллия: его содержание в волосах уменьшалось при увеличении потребления белка, жиров, витаминов $\mathrm{B}_{1}$ и $\mathrm{B}_{12}$, а также $\mathrm{Na}$ и $\mathrm{Fe}$ (во всех случаях $\left.p \leq 0,001\right)$. Таким образом, полученные данные свидетельствуют о том, что недостаточное поступление различных нутриентов может в значительной степени влиять на обеспеченность организма целым рядом химических элементов. Причем перечень химических элементов различен для разных нутриентов.

КЛЮЧЕВЫЕ СЛОВА: рацион питания, элементный состав волос, студенты, РУДН, калий, цинк, молибден, хром, холин.

\section{ВВЕДЕНИЕ}

Обеспеченность организма химическими элементами (ХЭ) зависит прежде всего от их поступления с пищей. Алиментарное поступление ХЭ может сильно варьировать в разных регионах, а также внутри одного региона, так как содержание макро- и особенно микро- и ультрамикроэлементов в продуктах питания может значительно разниться (Skalnaya, Skalny, 2018; Гальченко, Назарова, 2019а; Гальченко, Назаро- ва, 2019б). Кроме того, на элементный статус организма могут оказывать влияние и другие факторы.

В первую очередь, это алиментарные причины дисбаланса, а именно: различные ХЭ могут вступать как в синергетические, так и в антагонистические отношения друг с другом, влияя на степень усвоения в желудочно-кишечном тракте, возможность накопления в различных тканях, скорость экскреции (Skalnaya, Skalny, 2018).

\footnotetext{
* Адрес для переписки:

Гальченко Алексей Владимирович

E-mail: gav.jina@gmail.com
}

(C) Микроэлементы в медицине, 2020 
Следует отметить, что абсорбция ХЭ может быть снижена при нарушении функции эпителия тонкого кишечника. Кишечная флора играет огромную роль в способности организма усваивать ХЭ, так как она влияет на моторику кишечника и, соответственно, скорость продвижения химуса, при этом кишечный микробиом сам продуцирует огромное количество биологически активных веществ, влияющих на всасываемость ХЭ (Скальная и др., 2004; Skalnaya, Skalny, 2018). Помимо этого, потребность во многих ХЭ увеличивается при инфекционных заболеваниях, при интенсивных занятиях спортом, в периоды активного роста, при беременности и лактации, острых и хронических кровопотерях и при других состояниях (Skalnaya, Skalny, 2018).

Перечисленные нарушения питания могут приводить к питательной (нутриентной) недостаточности и снижению адаптационно-компенсаторных и регуляторных возможностей организма, изменению его физиологических функций, способствуя формированию и распространению алиментарно-зависимых неинфекционных заболеваний (Скальная и др., 2004; Сергеев и др., 2016).

Ц е л ь и с с л е д о в а н и я - определить взаимосвязь содержания химических элементов в биосубстратах организма с характером питания.

\section{МАТЕРАЛЫ И МЕТОДЫ}

Данное исследование является обсервационным, поперечным. Обследовано 107 человек (75 женщин и 32 мужчины), студентов первого курса ФГАОУ ВО «Российский университет дружбы народов» из 33 стран Северной и Южной Америки, Африки, Европы и Азии. Средний возраст испытуемых составил 22 года (18-50 лет): мужчин - 23 года (18-38 лет), женщин - 22 года (20-50 лет).

Забор биоматериала для исследования (волос) осуществляли с пяти участков затылочной области испытуемых. С каждого участка отбирали $\sim 0,1$ мг волос. Затем волосы помещали в чистые бумажные конверты и транспортировали в клинико-диагностическую лабораторию АНО «Центр биотической медицины» (Москва). Подготовку биоматериала к исследованию выполняли в соответствии с методическими рекомендациями «Порядок забора, хранения и транспортировки биосубстратов для определения химиче- ских элементов». Содержание химических элементов в волосах оценивали методом массспектрометрии с индуктивно связанной плазмой на аппарате Nexion 300D (Perkin-Elmer, США) (Serebryansky et al., 2002; Скальный, 2003).

Фактическое питание оценивали методом частотного анализа с программным обеспечением «Nutrilogic» (OOO «Нутрилоджик», г. Рязань). Учитывали потребление продуктов питания за 36 месяцев-

Статистическую обработку данных проводили с помощью пакета прикладных программ SPSS 23. Анализ результатов исследования осуществляли с применением описательной статистики. Выборка не была репрезентативной, соответственно данные представлены в виде медианы и квартилей. Межгрупповое сравнение качественных признаков оценивали критерием $\chi^{2}$. Различие двух независимых групп определяли критерием Манна-Уитни.

\section{РЕЗУЛЬТАТЫ}

Результаты проведенного корреляционного анализа содержания ХЭ в волосах и потребления различных пищевых веществ у мужчин показали, что потребление витамина $\mathrm{B}_{12}$ выше у испытуемых с более высокими концентрациями фосфора $(r=0,596, p=0,0001)$, кальция $(r=0,501, p=0,047)$, и кобальта $(r=0,417, p=0,003)$ в волосах. Содержание фосфора выше у пациентов с более значительным потреблением пантотеновой кислоты $(r=0,575, p=0,001)$. Кроме того, повышение потребления пантотеновой кислоты наблюдалось у испытуемых с более низким содержанием магния в волосах $(r=-0,539, p=0,0001)$. Снижение концентраций магния отмечалось и при снижении потребления фолиевой кислоты $(r=0,440, p=0,001)$. Концентрации ртути были выше при уменьшении количества $\beta$-каротина в рационе $(r=-0,432$, $p=0,002)$. Также обнаружено, что увеличение потребления хрома $(r=-0,762, p=0,028)$, никеля $(r=-0,786, \quad p=0,021) \quad$ и молибдена $(r=-0,714$, $p=0,047)$ обратно коррелировало с концентрацией серебра в волосах, а потребление марганца $(r=-0,738, p=0,037)$, кобальта $(r=-0,762, p=0,028)$, молибдена $(r=-0,857, p=0,007)$, никеля $(r=-0,786$, $p=0,021)$ и хрома $(r=-0,810, p=0,015)-\mathrm{c}$ содержанием вольфрама.

У женщин получены весьма интересные результаты: обнаружена зависимость потребления различных нутриентов только с концентрациями 
бериллия. Однако содержание этого ХЭ в волосах значимо ( $p=0,001$ для всех корреляций) снижалось при увеличении потребления кобаламина $(r=-0,518)$, тиамина $(r=-0,474)$, железа $(r=-0,506)$, натрия $(r=-0,466)$ и даже белка $(r=-0,455)$ и жиров $(r=-0,440)$. Полные результаты корреляционного анализа по концентрациям ХЭ в волосах и пищевому статусу представлены в табл. 1.

Таблица 1. Корреляционный анализ содержания химических элементов в волосах и потребления различных пищевых веществ у мужчин

\begin{tabular}{|c|c|c|c|c|}
\hline Химический элемент & Зависимость & Нутриент & $r$ & $p$ \\
\hline \multirow[t]{3}{*}{ Ag } & $\downarrow$ & Mo & $-0,714$ & 0,047 \\
\hline & $\downarrow$ & $\mathrm{Ni}$ & $-0,786$ & 0,021 \\
\hline & $\downarrow$ & $\mathrm{Cr}$ & $-0,762$ & 0,028 \\
\hline \multirow[t]{5}{*}{$\mathrm{W}$} & $\downarrow$ & $\mathrm{Cr}$ & $-0,810$ & 0,015 \\
\hline & $\downarrow$ & $\mathrm{Ni}$ & $-0,786$ & 0,021 \\
\hline & $\downarrow$ & Mo & $-0,857$ & 0,007 \\
\hline & $\downarrow$ & Co & $-0,762$ & 0,028 \\
\hline & $\downarrow$ & $\mathrm{Mn}$ & $-0,738$ & 0,037 \\
\hline $\mathrm{Zr}$ & $\uparrow$ & $\mathrm{V}$ & 0,714 & 0,047 \\
\hline Ga & $\downarrow$ & $\mathrm{Ni}$ & $-0,738$ & 0,037 \\
\hline $\mathrm{Ca}$ & $\uparrow$ & Кобаламин & 0,501 & 0,047 \\
\hline Co & $\uparrow$ & Кобаламин & 0,417 & 0,003 \\
\hline $\mathrm{Hg}$ & $\downarrow$ & $\beta$-Каротин & $-0,432$ & 0,002 \\
\hline \multirow[t]{2}{*}{$\mathrm{Mg}$} & $\uparrow$ & Фолат & 0,440 & 0,001 \\
\hline & $\downarrow$ & Пантотеновая кислота & $-0,539$ & 0,0001 \\
\hline Mo & $\downarrow$ & $\mathrm{Na}$ & $-0,762$ & 0,028 \\
\hline \multirow[t]{2}{*}{$\mathrm{P}$} & $\uparrow$ & Кобаламин & 0,596 & 0,0001 \\
\hline & $\uparrow$ & Пантотеновая кислота & 0,575 & 0,001 \\
\hline
\end{tabular}

Ниже приведены данные распространенности дефицита отдельных нутриентов в исследованной группе относительно «Норм физиологических потребностей в энергии и пищевых веществах для различных групп населения Российской Федерации. Методические рекомендации. М.: Федеральный центр гигиены и эпидемиологии Роспотребнадзора, 2009. 36 с.» (Нормы физиологических потребностей..., 2009) (* - данные представлены в виде частот, анализ различия произведен по критерию $\chi^{2}$ ), \%:

Белки $.11,21$

Жиры $.11,21$

Углеводы 30,84

Натрий ...6,54

Калий ..16,82

Кальций $.39,25$
Магний 29,91

Фосфор 61,68

Железо 12,15

Бор 27,10

Йод 57,01

Кобальт.. 24,30

Марганец 8,41

Медь . 14,95

Молибден $75,70 *$

Селен 14,02

Хром 78,50 *

Цинк. 36,45

Витамин А..................................................... 30,84

Тиамин........................................................... 26,

Рибофлавин ……………………………….... .24,30

Холин $71,96 *$ 
При анализе рационов выявлено пониженное потребление хрома с пищей у 79\% обследуемых, молибдена - у 76\%, холина - 72\%, йода у 57\%. При этом в ходе оценки взаимосвязи потребляемого молибдена с другими элементами наблюдалась корреляция с кобальтом, потребляемым с пищей $(r=0,761 p<0,05)$, а также медью, никелем, фтором и хромом, потребляемыми с пищей $(r=0,624, p<0,05 ; r=0,943, p<0,05 ; r=0,718$, $p<0,05$ и $r=0,968, p<0,05$ соответственно). Определена взаимосвязь потребления молибдена с потреблением витаминов С и Н (биотин) - $r=0,646$, $p<0,05$ и $r=0,613, p<0,05$.

Кроме этого, проведено сравнение групп, у которых был дефицит потребления с пищей молибдена, хрома и холина (см. табл. 2-4).

Таблица 2. Сравнительный анализ содержания химических элементов в волосах у пациентов с дефицитом и нормой потребления молибдена

\begin{tabular}{|c|c|c|c|}
\hline Элемент & Группа пациентов с дефицитом потребления & Группа пациентов с нормой потребления & $p$ \\
\hline K & $133,318[51,871 ; 315,98]$ & $188,72[47,26 ; 354,25]$ & 0,0649 \\
\hline Zn & $182,877[147,464 ; 237,6]$ & $189,13[149,76 ; 259,74]$ & 0,0637 \\
\hline Мо & $0,024[0,016 ; 0,027]$ & $0,035[0,031 ; 0,059]$ & 0,0786 \\
\hline
\end{tabular}

П р и м е ч а н и е : данные представлены в виде медианы и квартилей. Анализ различий проведен по критерию МаннаУитни, $p<0,05$.

Таблица 3. Сравнительный анализ содержания химических элементов в волосах у пациентов с дефицитом и нормой потребления хрома

\begin{tabular}{|c|c|c|c|}
\hline Элемент & Группа пациентов с дефицитом потребления & Группа пациентов с нормой потребления & $p$ \\
\hline $\mathrm{Al}$ & $5,67[4,07 ; 10,4]$ & $8,26[5,48 ; 12,11]$ & 0,0502 \\
\hline $\mathrm{Cr}$ & $0,19[0,06 ; 0,46]$ & $0,49[0,34 ; 0,73]$ & 0,0571 \\
\hline $\mathrm{Fe}$ & $21,5[12,36 ; 31,51]$ & $32,46[18,11 ; 35,61]$ & 0,0649 \\
\hline
\end{tabular}

П р и м е ч а н и е : см. табл. 2 .

Таблица 4. Сравнительный анализ содержания химических элементов в волосах у пациентов с дефицитом и нормой потребления холина

\begin{tabular}{|c|c|c|c|}
\hline Элемент & Группа пациентов с дефицитом потребления & Группа пациентов с нормой потребления & $p$ \\
\hline K & $133,38[51,81 ; 314,08]$ & $188,72[47,26 ; 340,2]$ & 0,0575 \\
\hline I & $0,44[0,16 ; 0,93]$ & $0,372[0,26 ; 0,62]$ & 0,0546 \\
\hline Zn & $182,81[147,46 ; 257,06]$ & $201,331[149,7 ; 283,7]$ & 0,0584 \\
\hline
\end{tabular}

П р и м е ч а н и е : см. табл. 2 .

Показатели ХЭ в волосах у данных пациентов сравнивались с группами пациентов, у которых их потребление было в норме. В результате анализа определено, что у пациентов с дефицитом и нормой потребления молибдена отмечаются различия в содержании кальция, калия, молибдена и цинка в волосах.

При дефиците потребления хрома, межгрупповое различие определялось по содержанию в волосах алюминия, хрома и железа.

Следует отметить, что различие в группах по содержанию йода, калия и цинка в волосах установлено при дефиците потребления холина.

\section{ОБСУЖДЕНИЕ}

Поскольку исследование являлось обсервационным поперечным, не представлялось возможным оценить другие факторы, помимо питания, и случайные воздействия, которые были способны повлиять на химический состав волос. Также весомым ограничением явилась невозможность исследовать статус обследованных в динамике. Сравнительно небольшой объем выборки и значительный разброс данных также негативно сказались на уровне достоверности статистических расчетов. Кроме того, существенная разница в количественном составе по- 
ловых групп исключила возможность проводить межгрупповые сравнения по половому признаку. Число обследованных мужчин в целом было невелико (32 человека), что снизило эффективность статистических расчетов.

Анализируя полученные корреляционные отношения, необходимо отметить, что взаимосвязь содержания кобальта в волосах и витамина $\mathrm{B}_{12}$ в рационе свидетельствует о том, что основная биологическая роль кобальта у человека проявляется именно в виде витамина $\mathrm{B}_{12}$ (Herbert, 1988). Основным антагонистом вольфрама является молибден, поэтому наиболее сильная обратная корреляция наблюдалась именно при анализе этих двух химических элементов. В меньшей степени антагонизм по отношению к вольфраму проявляют и другие металлы, что также удалось обнаружить (Maia et al., 2014; Zoroddu et al., 2018). Повышенное потребление натрия может способствовать развитию дефицита молибдена, что отразилось на полученных результатах (Скальная, Нотова, 2004; Бакулин, Мусаева, 2006). Установлено, что алюминий может тормозить усвоение многих химических элементов и витаминов. Кроме того, избыточное поступление алюминия способствует развитию дефицита метионина, поступление которого может быть и так недостаточным у групп людей, не потребляющих продукты животного происхождения (Venti, Johnston, 2002; McCarty et al., 2009; Гальченко и др., 2017; Skalnaya, Skalny, 2018). Экскреция хрома с мочой закономерно повышалась при увеличении потребления углеводов, жиров, белков и энергетической ценности рациона в целом, так как этот элемент участвует в передаче сигнала инсулина (Vincent, 2000a; Vincent, 2000b; Cefalu, Hu, 2004; Guerrero-Romero, RodríguezMorán, 2005; Vincent, 2011; Abdollahi et al., 2013).

Схожие работы обнаружены и у других авторов. Так, в исследовании В.В. Скального проводилась оценка содержания ХЭ в волосах работников ОАО «Северсталь» и их нутриентного статуса и сравнение этих показателей. Уровень эссенциальных ХЭ (за исключением калия) в волосах испытуемых был ниже при более значительном потреблении практически всех витаминов (A, C, E, K, B $, B_{2}, B_{5}, B_{12}$, PР). У лиц рабочих специальностей, интенсивно контактировавших с металлами на производстве, отмечалась положительная корреляция между содержанием металлов в волосах и поступлением с пищей витами- нов, поступлением с пищей ХЭ. У них же обнаружена положительная корреляция между потреблением белка и концентрациями К и Se в волосах, витаминов $\mathrm{B}_{2}, \mathrm{~B}_{12}$ и $\mathrm{PP}$ - и содержанием К. Автор заключил, что повышение алиментарного поступления в организм микронутриентов в целом способствует более интенсивной элиминации бериллия, мышьяка, ртути, кобальта, лития, ванадия, титана. Однако микронутриентная ценность рациона, вероятно, не оказывает влияния на экскрецию кадмия, свинца, олова и железа. Богатая белком пища, по всей видимости, способствует восстановлению нарушенных функций нейромышечной проводимости, водносолевого баланса, гуморального иммунитета, дезинтоксикационной функции печени и антиоксидантной системы, таким образом уменьшая потребность в калии и селене и увеличивая экскрецию этих ХЭ. В то же время у испытуемых, не подверженных интоксикации тяжелыми металлами, изменения нутриентного состава рациона не вызывали таких сдвигов в содержании ХЭ в волосах. Автор полагает, что нехватка йода, цинка, магния, кальции, меди и калия во многом может быть обусловлена их алиментарным дефицитом, либо недостаточным поступлением их синергистов - витаминов A, B 6 , D, C, особенно у людей рабочих профессий (Скальный, 2008).

И.Г. Бакулин и Э.А. Мусаева в своем исследовании оценивали эффективность применения мультиминерального комплекса «Спектрамин» при коррекции элементных нарушений у пациентов с артериальной гипертензией. Так, концентрации кальция и хрома в венозной крови достоверно увеличились после курса приема препарата. В то же время концентрации меди и марганца снизились, несмотря на то, что эти элементы также содержались в препарате. Вероятно, это было связано с антагонистическим воздействием других компонентов препарата, таких как цинк и железо. Также было обнаружено умеренное повышение концентраций лития (Бакулин, Мусаева, 2006).

В исследовании М.Г. Скальной и С.В. Нотовой отмечена положительная корреляция между потреблением марганца и содержанием этого элемента в волосах у женщин $(p<0,001)$. Для других элементов подобной зависимости обнаружено не было (Скальная, Нотова, 2004).

В работе Т.И. Бурцевой также выявлена прямая корреляция алиментарного поступления мар- 
ганца с его концентрациями в волосах учащихся колледжей Оренбургского государственного университета. Такая же зависимость была обнаружена и для хрома. Также показано, что недостаточнее поступление цинка, йода и селена с пищей коррелирует с пониженным содержанием этих элементов в волосах (Бурцева, 2006). Кроме того, автор полагает, что одной из главных причин высокой распространенности дефицита селена в Оренбургской области является низкое содержание селена в почвах и воде, и, следовательно, в продуктах питания (Бурцева, 2016).

D.J. Tueller с соавт., в свою очередь, не обнаружили достоверной корреляции содержания ХЭ в волосах с их алиментарным поступлением у жителей Перу и США (Tueller et al., 2013).

Интересные данные получены в исследовании канадских авторов. L.-A. Dion с соавт. выявили, что значительное поступление с водой марганца ассоциировалось с более высокими показателями IQ у детей - мальчиков. У девочек же наблюдалось обратное явление. При этом концентрация марганца в волосах никак не была связана с показателями IQ у детей обоих полов (Dion et al., 2018).

\section{ВЫВОДЫ}

Более половины студентов первого года обучения потребляют недостаточно P, I, Mo, Cr и холина. Причем, обнаружены значительные различия химического состава волос при сравнении групп, дефицитных и профицитных по потреблению Мо, Сr и холина.

Полагаем, что полученные данные следует использовать при коррекции элементного статуса организма и уровня его функциональных резервов, сниженных в результате воздействия неблагоприятных факторов окружающей среды.

\section{ЛИТЕРАТУРА}

Бакулин И.Г., Мусаева Э.А. Элементный статус у больных артериальной гипертонией при применении мультиминерального комплекса. Вестник Оренбургского государственного университета. Приложение «Биоэлементология». 2006; 12(62): 28-30.

Бурцева Т.И. Особенности питания и элементный состав волос учащихся колледжей Оренбургского государственного университета. Автореф. дисс. ... канд. биол. наук. M. 2006.

Бурцева Т.И. Совершенствование системы экологического мониторирования селенового статуса населения (на примере Оренбургской области). Автореф. дисс. ... докт. мед. наук. М. 2016.
Гальченко А.В., Морозова Л.Д., Залетова Т.С. Оценка потребности в белке и аминокислотах, исходя из биосинтетических потребностей и показателей азотистого баланса. Вопросы диетологии. 2017; 7(2): 64-68. doi: 10.20953/22245448-2017-2-64-68.

Гальченко А.В., Назарова А.М. Макроэлементы в питании вегетарианцев и веганов. Микроэлементы в медицине. 2019; 20(2): 3-17. doi: 10.19112/2413-6174-2019-20-2-3-17.

Гальченко А.В., Назарова А.М. Эссенциальные микро-и ультрамикроэлементы в питании вегетарианцев и веганов. Часть 1. Железо, цинк, медь, марганец. Микроэлементы в медицине. 2019; 20(4): 14-23. doi: 10.19112/2413-61742019-20-4-14-23.

Нормы физиологических потребностей в энергии и пищевых веществах для различных групп населения Российской Федерации. Методические рекомендации. М.: Федеральный центр гигиены и эпидемиологии Роспотребнадзора. 2009. 36 c.

Сергеев В.Н., Михайлов В.И., Шестопалов А.Е., Тарасова Л.В. Значение лечебно-профилактического питания в комплексном лечении заболеваний. Вестник неврологии, психиатрии и нейрохирургии. 2016; 8(79): 70-74.

Скальная М.Г., Нотова С.В. Макро- и микроэлементы в питании современного человека: эколого-физиологические и социальные аспекты. М.: «РОСМЭМ». 2004. 310 с.

Скальная М.Г., Дубовой Р.М., Скальный А.В. Химические элементы-микронутриенты как резерв восстановления здоровья жителей России. Под ред. акад. РАМН В.А. Тутельяна, проф. И.П. Бобровницкого. Оренбург: РИК ГОУ ОГУ. 2004. 239 с.

Скальный А.В. Референтные значения концентрации химических элементов в волосах, полученные методом ИСП-АЭС (АНО «Центр биотической медицины»). Микроэлементы в медицине. 2003; 4(1): 7-11.

Скальный В.В. Восстановительная коррекция функционального состояния организма на основе пищенутрицевтической оптимизации элементного статуса у работников металлургического предприятия. Атореф. дисс. ... канд. мед. наук. М. 2008.

Abdollahi M., Farshchi A., Nikfar S., Seyedifar M. Effect of Chromium on Glucose and Lipid Profiles in Patients with Type 2 Diabetes; A Meta-analysis Review of Randomized Trials. Journal of Pharmacy \& Pharmaceutical Sciences. 2013; 16(1): 99. doi:10.18433/j3g022.

Cefalu W.T., Hu F.B. Role of Chromium in Human Health and in Diabetes. Diabetes Care. 2004; 27(11): 27412751. doi:10.2337/diacare.27.11.2741.

Dion L.-A., Saint-Amour D., Sauvé S., Barbeau B., Mergler D., Bouchard M.F. Changes in water manganese levels and longitudinal assessment of intellectual function in children exposed through drinking water. NeuroToxicology. 2018; 64: 118125. doi:10.1016/j.neuro.2017.08.015.

Guerrero-Romero F., Rodríguez-Morán M. Complementary Therapies for Diabetes: The Case for Chromium, Magnesium, and Antioxidants. Archives of Medical Research. 2005; 36(3): 250-257. doi:10.1016/j.arcmed.2005.01.004.

Herbert V. Vitamin B-12: plant sources, requirements, and assay. The American Journal of Clinical Nutrition. 1988; 48(3): 852-858. doi:10.1093/ajcn/48.3.852. 
Maia L.B., Moura J.J. G., Moura I. (). Molybdenum and tungsten-dependent formate dehydrogenases. JBIC Journal of Biological Inorganic Chemistry. 2014; 20(2): 287309. doi:10.1007/s00775-014-1218-2.

McCarty M., Barroso-Aranda J., Contreras F. The lowmethionine content of vegan diets may make methionine restriction feasible as a life extension strategy. Medical Hypotheses. 2009; 72(2): 125-128.

Serebryansky E.P., Skalny A.V., Kuznetsov V.V. Rapid ICP-OES determination of up to 20 essential and toxic elements in human hair for estimation of human microelemental status. Proc. 21 Workshop Macro and Trace Elements. Jena, Germany. October 18-19 2002: 19-24.

Skalnaya M.G., Skalny A.V. Essential trace elements in human health: a physician's view. Tomsk: Publishing House of Tomsk State University. 2018. 224 p.

Tueller D.J., Eggett D.L., Parker T.L. A preliminary study of a Peruvian diet using dietary analysis and hair mineral content as indicators. Biol Trace Elem Res. 2013. Nov; 155(2): 161-168. doi: 10.1007/s12011-013-9774-9.

Venti C., Johnston C. Modified food guide pyramid for lactovegetarians and vegans. J. Nutr. 2002; 132(5): 1050-1054.

Vincent J.B. Elucidating a Biological Role for Chromium at a Molecular Level. Accounts of Chemical Research. 2000; 33(7): 503-510. doi:10.1021/ar990073r.

Vincent J.B. Chromium: Biological Relevance. Encyclopedia of Inorganic and Bioinorganic Chemistry. 2011. doi:10.1002/9781119951438.eibc0040.

Vincent J.B. The Biochemistry of Chromium. The Journal of Nutrition. 2000; 130(4): 715-718. doi:10.1093/jn/130.4.715.

Zoroddu M.A., Medici S., Peana M., Nurchi V.M., Lachowicz J.I., Laulicht-Glickc F., Costa M. Tungsten or Wolfram: Friend or Foe? Current Medicinal Chemistry. 2018; 25(1): 65-74. doi:10.2174/0929867324666170428105603.

\title{
ASSOCIATION OF CHEMICAL HAIR CONTENT WITH NUTRITIONAL CHARACTERISTICS IN FIRST GRADE PFUR STUDENTS
}

\author{
A.V. Galchenko ${ }^{1,2}$, M.Y. Yakovlev ${ }^{1}$, A.A. Skalny ${ }^{1}$, A.A. Kirichuk ${ }^{1}$, \\ O.Yu. Orlova ${ }^{3}$, R. Almasry ${ }^{1}$, A.V. Barinov' ${ }^{1}$, N.V. Titov ${ }^{1}$, T.V. Korobeynikova ${ }^{4}$
}

\author{
${ }^{1}$ Peoples` Friendship University of Russia, Miklukho-Maklaya str. 6, 117198, Moscow, Russia \\ ${ }^{2}$ Federal State Budgetary Scientific Institution Federal Research Centre of Nutrition, Biotechnology and Food Safety, \\ Ust'inskiy Proezd Str. 2/14, 109240, Moscow, Russia \\ ${ }^{3}$ ITMO University, Kronverksky pr. 49, 197101, St. Petersburg \\ ${ }^{4}$ ANO Center for Biotic Medicine, Zemlyanoi Val 46, Moscow, 105064, Russia
}

ABSTRACT. The aim of the study was to determine the relationship of the content of chemical elements in the hair with the nature of nutrition. We examined 107 people (75 women and 32 men), first-year students of the Peoples` Friendship University of Russia from 33 countries. The average age of the subjects was 22 years. The hair was taken from the occipital part of the head. Hair was analyzed for qualitative and quantitative elemental composition by induced coupled plasma mass spectrometry. The average dietary intake of students was assessed by the method of frequency analysis using the Nutrilogic software. The results of the study showed that more than half of the students had a deficiency in consumption of P (61.68\%), I (57.01\%), Mo (75.70\%), Cr (78.50\%), choline (71.96\%). The strongest correlations of the content of the chemical elements in the hair with the intake of nutrients in men were found for (chemical element in the hair - nutrient, dependence, direct or inverse, p value) W - Mo, $\downarrow$, 0.007; Co - vitamin B12, $\uparrow, 0.003$, Hg $\beta$-carotene, $\downarrow, 0.002 ; \mathrm{Mg}$ - folate, $\uparrow, 0.001 ; \mathrm{Mg}$ - pantothenic acid, $\downarrow, 0.0001 ; \mathrm{P}$ - vitamin B12, $\uparrow, 0.0001 ; \mathrm{P}$ - pantothenic acid, $\uparrow, 0.001$. No such relationships were found among women, with the exception of beryllium concentrations: its content in the hair decreased with an increase in the intake of protein, fats, vitamins B1 and B12, as well as Na and Fe (in all cases, $\mathrm{p} \leq 0.001$ ). Thus, the data obtained indicate that insufficient intake of various nutrients can significantly affect the status of a number of chemical elements. Moreover, the list of chemical elements is different for different nutrients. choline.

KEYWORDS: diet, elemental composition of hair, students, PFUR, potassium, zinc, molybdenum, chromium,

\section{REFERENCES}

Bakulin I.G., Musaev E.A. Elementnyi status u bol'nykh arterial'noi gipertoniei pri primenenii multimineral'nogo kompleksa. Vestnik Orenburgskogo universiteta. Prilozhenie «Bioelementologiya». 2006; 12(62): 28-30 (in Russ.).

Burtseva T.I. Osobennosti pitaniya i elementnyi sostav volos uchashchikhsya kolledzhei Orenburgskogo gosudarstvennogo universiteta. Avtoref. diss. ... kand. biol. nauk. M. 2006 (in Russ.).

Burtseva T.I. Sovershenstvovanie sistemy ekologicheskogo monitorirovaniya selenovogo statusa naseleniya (na primere Orenburgskoi oblasti). Avtoref. diss. ... dokt. med. nauk. M. 2016 (in Russ.).

Galchenko A.V., Morozova L.D., Zaletova T.S. Evaluation of protein and amino acid requirements, based on biosynthetic needs and nitrogen balance parameters. Vopr. dietol. (Nutrition). 2017; 7(2): 64-68. (In Russ.). DOI: 10.20953/2224-5448-2017-264-68. 
Galchenko A.V., Nazarova A.M. Macroelements in nutrition of vegetarians and vegans (review). Trace Elem. Med.2019; 20(2): 3-17. (in Russ.).

Galchenko A.V., Nazarova A.M. Eessential trace and ultra trace elements in nutrition of vegetarians and vegans. Part 1. Iron, zinc, copper, manganese. Trace Elem. Med. 2019; 20(4): 14-23. (in Russ.).

Normy fiziologicheskikh potrebnostei v energii i pishchevykh veshchestvakh dlya razlichnykh grupp naseleniya Rossiiskoi Federatsii. Metodicheskie rekomendatsii. M.: Federal'nyi tsentr gigieny i epidemiologii Rospotrebnadzora. 2009. 36 s. (in Russ.).

Sergeev V.N., Mikhailov V.I., Shestopalov A.E., Tarasova L.V. Znachenie lechebno-proilakticheskogo pitaniya v kompleksnom lechenii zabolevanii. Vestnik nevrologii, psikhiatrii i neirokhirurgii. 2016; 8(79): 70-74 (in Russ.).

Skalnaya M.G., Notova S.V. Makro- i mikroelementy v pitanii sovremennogo cheloveka: ekologo-iziologicheskie i sotsial'nye aspekty. M.: «ROSMEM». 2004. 310 s. (in Russ.).

Skalnaya M.G., Dubovoi R.M., Skalny A.V. Khimicheskie element-mikronutrienty kak rezerv vosstanovleniya zdorov'ya zhitelei Rossii. Pod red. akad. RAMN V.A. Tutel'yana, prof. I.P. Bobrovitskogo. Orenburg: RIK GOU OGU. 2004. 239 s. (in Russ.).

Skalny A.V. Referentnye znacheniya kontsentratsii khimicheskikh elementov v volosakh, poluchennykh metodom isp-aes (ANO «Tsentr bioticheskoi meditsiny»). Mikroelementy v meditsine. 2003; 4(1): 7-11 (in Russ.).

Skalny V.V. Vosstanovitel'naya korrektsiya funktsional'nogo sostoyaniya organizma na osnove pishchenutritsevticheskoi optimizatsii elementnogo statusa u rabotnikov metallurgicheskogo predpriyatiya. Avtoref. diss. ... kand. biol. nauk. M. 2008 (in Russ.).

Abdollahi M., Farshchi A., Nikfar S., Seyedifar M. Effect of Chromium on Glucose and Lipid Profiles in Patients with Type 2 Diabetes; A Meta-analysis Review of Randomized Trials. Journal of Pharmacy \& Pharmaceutical Sciences. 2013; 16(1): 99. doi:10.18433/j3g022.

Cefalu W.T., Hu F.B. Role of Chromium in Human Health and in Diabetes. Diabetes Care. 2004; 27(11): $2741-2751$. doi:10.2337/diacare.27.11.2741.

Dion L.-A., Saint-Amour D., Sauvé S., Barbeau B., Mergler D., Bouchard M.F. Changes in water manganese levels and longitudinal assessment of intellectual function in children exposed through drinking water. NeuroToxicology. 2018; 64: 118-125. doi:10.1016/j.neuro.2017.08.015.

Guerrero-Romero F., Rodríguez-Morán M. Complementary Therapies for Diabetes: The Case for Chromium, Magnesium, and Antioxidants. Archives of Medical Research. 2005; 36(3): 250-257. doi:10.1016/j.arcmed.2005.01.004.

Herbert V. Vitamin B-12: plant sources, requirements, and assay. The American Journal of Clinical Nutrition. 1988; 48(3): 852-858. doi:10.1093/ajcn/48.3.852.

Maia L.B., Moura J.J. G., Moura I. (). Molybdenum and tungsten-dependent formate dehydrogenases. JBIC Journal of Biological Inorganic Chemistry. 2014; 20(2): 287-309. doi:10.1007/s00775-014-1218-2.

McCarty M., Barroso-Aranda J., Contreras F. The lowmethionine content of vegan diets may make methionine restriction feasible as a life extension strategy. Medical Hypotheses. 2009; 72(2): 125-128.

Serebryansky E.P., Skalny A.V., Kuznetsov V.V. Rapid ICP-OES determination of up to 20 essential and toxic elements in human hair for estimation of human microelemental status. Proc. 21 Workshop Macro and Trace Elements. Jena, Germany. October 18-19 2002: 19-24.

Skalnaya M.G., Skalny A.V. Essential trace elements in human health: a physician’s view. Tomsk: Publishing House of Tomsk State University. 2018. 224 p.

Tueller D.J., Eggett D.L., Parker T.L. A preliminary study of a Peruvian diet using dietary analysis and hair mineral content as indicators. Biol Trace Elem Res. 2013. Nov; 155(2): 161-168. doi: 10.1007/s12011-013-9774-9.

Venti C., Johnston C. Modified food guide pyramid for lactovegetarians and vegans. J. Nutr. 2002; 132(5): 1050-1054.

Vincent J.B. Elucidating a Biological Role for Chromium at a Molecular Level. Accounts of Chemical Research. 2000; 33(7): 503-510. doi:10.1021/ar990073r.

Vincent J.B. Chromium: Biological Relevance. Encyclopedia of Inorganic and Bioinorganic Chemistry. 2011. doi:10.1002/9781119951438.eibc0040.

Vincent J.B. The Biochemistry of Chromium. The Journal of Nutrition. 2000; 130(4): 715-718. doi:10.1093/jn/130.4.715.

Zoroddu M.A., Medici S., Peana M., Nurchi V.M., Lachowicz J.I., Laulicht-Glickc F., Costa M. Tungsten or Wolfram: Friend or Foe? Current Medicinal Chemistry. 2018; 25(1): 65-74. doi:10.2174/0929867324666170428105603. 